\title{
Processos argumentativos como recursos de interacão em aulas
}

\author{
Paulo de Tarso GALEMBECK \\ Universidade Estadual de Londrina
}

Palavras-chave: língua falada; interação; argumentação; aulas.

Resumo: Este texto trata dos processos argumentativos empregados em aulas para os ensinos médio e superior. É enfatizado o fato de que o uso desses procedimentos só pode ser compreendido dentro da situação específica de comunicação e interação, a aula. Os procedimentos de mais alta freqüência são as relações causais (causa e conseqüência), as citações ou testemunhas, os exemplos, que são aqueles que mais adaptam à interação em aulas. Os demais procedimentos de argumentação requerem uma elaboração mental maior e, por isso, não são discutidos neste trabalho.

\begin{abstract}
This text deals with the argumentative procedures used in classes for high schools and colleges. It is emphasized that the use of these situation of communication and interaction, the class. The procedures of higher frequency are the causal relations (cause and consequence), the quotations or testimonies, the examples, because they are the more adaptable to the interaction in classrooms. The others procedures of argumentation need a deeper mental elaboration, and are not discussed in this paper.
\end{abstract}

Resumen: Este texto discute los procedimientos argumentativos empleados en clases de liceos y facultades. Se enfatiza que el empleo de estés procedimientos solo pude ser entendido en esta situación específica de comunicación (una dada clase). Los procedimientos demás alta frecuencia son las relaciones causales 
(causa y efecto), las citaciones e testimonios, los ejemplos, puesto que estés son los recursos que más se adaptan a las clases. Los otros procedimientos de argumentación requieren una elaboración más profunda, y no son discutidos en este texto.

\section{Introdução}

O objetivo desta exposição é discutir o papel dos procedimentos argumentativos no processo de interação que se estabelece em aulas para os ensinos secundário e superior. Pretende-se, com essa discussão, apresentar os referidos procedimentos a partir das particularidades de uma situação especifica de interação (a aula), do modo de atuação dos participantes desse evento interacional e da relação ou contrato que se estabelece em função desse quadro interacional (Charaudeau, 1984).

$\mathrm{Na}$ análise que e propõe efetuar, é preciso levar em conta que os procedimentos argumentativos são utilizados em uma situação de interação assimétrica, representada pelas aulas expositivas. Nesses eventos, há uma pessoa que dirige o processo de interação, o "mestre"; ele detém o monopólio da palavra e é, geralmente, o único responsável pelo desenvolvimento do tópico e participação dos ouvintes (os alunos) só ocorre em momentos determinados, mediante a sanção do professor.

$\mathrm{O}$ corpus deste trabalho é constituído por inquéritos do tipo EF (Elocução Formal), pertencentes dos arquivos dos Projetos NURC/SP (inqs. 124, 338, 377, 405) e NURC/RJ $(251,384,382)$ Trata-se da gravação de aulas para os ensinos secundário e superior, e nelas vai ser feita a análise dos processos argumentativos utilizados no decorrer da exposição. Cabe ressalvar, porém, que nem todos os processos citados têm igual representatividade no corpus, por isso mesmo, a exposição será limitada àqueles processos de maior recorrência no material estudado; relações de causa e conseqüência, exemplos, citações. 


\section{Causa}

Vejam-se os dois exemplos a seguir:

(Exemplo 01) - essa é a nossa preocupação... hoje...((tosse)) razoes ou motivo pelas quais as pessoas... éh:: demandam moeda... existem três motivos clássicos.., pelos quais as pessoas... retêm moeda... são três motivos... ou três razoes... que fazem com que se retenha moeda.., por motivo... tran-asação... existe uma demanda de moeda por motivo.. precaução... es/esses dois tipos de demanda de moeda já... já foram... éh discutidos pelos clássicos economistas clássicos... Keynes... introduziu.., uma nova razão pela qual as pessoas.., demandam moeda guardam moeda... demanda de moeda por motivo es-pe-culação...” (NURK/SP, 338, L. 22-36)

(Exemplo 02) - então daí.., podemos verificar em que medida o indivíduo pode... realizar (determinadas funções... assumir certas funções)... vocês verificam que - esses teste... surgi::ram... a partir:: de necessidades... PRAticas certo?... para atender problemas práticos... esse foi o motivo do surgimento dos teste.., por um lado.., para selecionar indivíduos.., para o trabalho... por outro lado para selecionar crianças::... eh:::... problemáticas... criança que::... não:: conseguiam acompanhar a escola.., certo? Então se procurou ter..." (NURC/SP, 277, L. 121-131)

No exemplo 01 (trecho de uma aula de Economia), o professor simplesmente expõe os três motivos que levam as pessoas a reterem moeda: transação, precaução, especulação. Trata-se de uma expansão do tópico (“aquilo de que se está falando", segundo Brown e Yule (1983, p.7)). Essa expansão tem a finalidade de apresentar os tópicos que serão discutidos no desenvolvimento da aula e, bem assim, de contextualizar as informações 
dentro daquilo que o professor acredita ser de conhecimento dos alunos, já que se trata de noções básicas de Economia e Finanças.

Essa mesma preocupação é verificada no exemplo 02: numa aula de Psicologia, o professor discorre acerca dos testes psicológicos e menciona as razões do surgimento desses testes: a seleção de funcionários e o acompanhamento de crianças na fase escolar. São duas situações de amplo conhecimento dos alunos, que, com certeza, já se submeteram a esses testes. Há uma preocupação em tornar mais concretas e palpáveis as informações recebidas. Essa mesma preocupação pode ser verificada no exemplo a seguir, no qual a professora menciona situações concretas, bem acessíveis a alunos (no caso, secundaristas), para explicar por que o homem medieval levava um tipo de vida nômade.

(Exemplo 03) - e eles viviam basicamente da coleta eram caçadores... e viviam da coleta... isto é levada a um tipo de vida nômade.., por quê?... porque na medida... em que acabava a caça do lugar $\mathrm{OU}$ (que) em virtude da da época do ano no inverno por exemplo... os animais iam hibernar outros... imigravam para lugares mais quentes eles também precisavam acompanhar... o a migração de caça se não eles iam ficar sem comer (NURC/SP, 405, L. 67-75)

No exemplo a seguir, pode-se verificar que a preocupação com a contextualização e o esclarecimento vem acompanhada da manifestação de opiniões.

(Exemplo 04) - então foi na época da industrialização né? No surgimento da revolução industrial::... que::... os testes foram muito úteis e se desenvolvera.., certo? Então nos tínhamos por um lado naquela época muitas crianças com problemas... e havia uma necessidade... de se pegar essas crianças... e adapta-las à escola co-mum né? Porque... quanto quanto mais uma criança possa (se) adaptar a uma escola comum... 
melhor... não há necessidade de formação... especial::: para educador:: e da disso né?... e por outro lado uma necessidade de de::: de desenvolvimento da indústria.., e a indústria o que que precisa? Maior produção... maior rendimento... né?...” (NURK/SP, 377, L. 144-151)

O professor procura mostrar por que surgiram os testes e apresenta a causa ou motivo, sob a forma não de um fato, mas de um juízo ou opinião: os testes surgiram para que a criança problemática pudesse adaptarse à escola comum e para que houvesse maior produtividade na indústria. Embora se trate de um juízo de valor, não é uma opinião marcadamente pessoal: ocorre antes a manifestação de juízo que se situa na esfera do senso comum. Alem disso, é preciso ressaltar que com esse procedimento o professor busca fazer com que os alunos participem do seu ponto de vista e venham assim, a adotar suas conclusões.

Esse mesmo caráter de manifestação de opiniões pode ser verificado no exemplo a seguir:

(Exemplo 05) - existe... na concepção estruturalista.., uma idéia de estrutura lingüística que demasiado rígida... para meu gosto... porque... o característico.., de todo organismo de todo sistema vivo.., é o contínuo devir e a mudança... contínua...” (NURC/SP, 124, L. 548-552)

No exemplo anterior, a manifestação de opiniões assume um caráter mais pessoal e subjetivo, que é indicado pela expressão para meu gosto. Com ela, o professor acentua que se trata de uma opinião marcadamente pessoal, mas há, de qualquer forma, a preocupação em encaminha os alunos para uma conclusão, para a aceitação das idéias do professor. 


\section{Conseqüência}

Nas ocorrências em que há a indicação da conseqüência, verifica-se a mesma preocupação em contextualizar os dados, de modo que os alunos passam situar-se em relação ao que é dito:

(Exemplo 06) - de varias amos::tras... de vários grupos que se submete::ram a esse teste... né?... ah:: verificou-se que :: numa regularidade... desses resultados... então se pôde éh::... construir ... padrões... né? pôde se estabelecer padrões... e as notas brutas dos outros indivíduos que vão se submeter aos testes... serão comparados... né?... as notas brutas serão comparadas... a esses padrões... então por exemplo se eu utilizo em teste... é sueco... no Brasil... eu tenho que primeiro... Adaptar essa mostra... sueca... esse paDRAO::... Ao padrão:: brasileiro então primeiro se aplica em vários grupos... quantos grupos... a estatística disser que é necessário... não é?... (e) então... passa-se a seguir a:: fazer um diagnóstico... dos indivíduos... né? Comparando-se a um padrão:: SIGNIFICATIVO DOS BRASILEIROS... “ (NURC/SP, 377, 1. 209-225)

(Exemplo 07) - se vocês tiverem que realizar., umas fazer umas continhas né? E::... se... vai comparar... a realização de vocês dentro daquele TEMpo::... que vocês tiveram.., para fazer aquelas conTinhas., em relação àquela escala de ansiedade... então vai se verificar se aqueles altos ansiosos... ou os baixos ansiosos.., vão realizar.., ah:: MAIS continhas.., num determinado tempo padrão... certo? E:: por exemplo se::.. os indivíduos vão realizar as continhas., numa seqüência determinada... “ (NURC/SP, 377, L. 67-76)

Em ambos os exemplos anteriores, extraídos de uma aula acerca de testes psicológicos, nota-se a mesma preocupação em expandir o tópico, 
para que os alunos possam situar-se contextualizar as asserções veiculadas. No exemplo 06, são discutidos os padrões de avaliação desses testes, e o professor enfatiza a necessidade de construírem-se padrões de comparação válidos para cada caso específico. No exemplo 07, ocorre a menção a uma situação específica, representada para aplicação do teste a indivíduos alto e baixo ansiosos. Em ambos os exemplos, verifica-se, ademais, a preocupação com o convencimento dos alunos, com o encaminhamento deles às conclusões a que o professor pretende fazê-los chegar.

No exemplo a seguir, a professora também procura encaminhar os alunos para uma conclusão, e manifesta, ademais, a sua opinião pessoal:

(Exemplo 08) - e que o estilo e que a arte SEMpre vão refletir uma determinada ma-NEIra... de considerar o mundo e a natureza... ora a maneira do homem pré-histórico era... Basicamente eu preciso comer.., e eu preciso::... me defender dos animais e eu preciso me esquentar na medida do possível.. certo?... então a arte pré-histórica só vai poder refletir::... então a arte vai nascer:: em função dessa Necessidade.., de se manter vivo.., necessidade que vai se caracterizar de forma PRINcipal:: em termos de comida... isto é de caça... que é o que oferece... uma resistência porque a:: fruta está na então eles não precisavam se preocupar... certo? Se a:: fruta se eles iam conseguir a fruta ou não.” (NURC/SP, 405, L. 107-119)

A professora parte de uma situação concreta (a luta do homem pré-histórico pela sobrevivência) e reitera, em forma de conclusão, que a arte pré-histórica espelha a necessidade de manter-se vivo. $\mathrm{O}$ uso desse procedimento argumentativo cumpre três funções: a) expande o tópico e permite contextualizar as informações em andamento; b) expõe o ponto de vista da "mestra"; c) encaminha os alunos para a conclusão desejada. 
(Exemplo 09) - existe uma infinidade de taxa de juros nós estamos jogando... como taxa de juros... tudo que é... tudo que é rendimento sobre título... ORTN LTN ações... certo? Éh bônus debêntures... evidente então existe uma... infinidade de taxa de juros... e a gente está supondo... como se fosse uma coisa só... uma taxa de juros... agregada mas na realidade existe um faMIlia de taxa de juros... certo?... mas para simplificar a exposição a gente sempre supõe... como se fosse... única... está okay bom... então nesse sentido... no fundo $\mathrm{O}$ que eu estou querendo estabelecer... assim como estabeleci como oferta de moeda uma relação entre oferta entre.. moeda e taxa de juros... e é essa e::... Como é... como é fei como foi feito Keynes basicamente ele... ele deu um papel bastante importante à taxa de juros como a gente falou.., então no fundo.., a demanda de moeda especulativa., ela depende... da taxa de juros... futura... e da taxa de juros... presente... aqui vista mais como um rendimento não é? (NURC/SP, 338, L. 485-505)

No exemplo anterior, o professor busca encaminhar os alunos para a conclusão, qual seja, que a demanda de moeda por especulação depende basicamente da taxa de juros. Para chegar a essa conclusão, ele afirma que a taxa de juros está sendo considerada como um todo (e não como um todo e não como uma família) e, bem assim, cita Keynes, processo que como vai ser vista a seguir confere à sua exposição maior credibilidade.

O exame dos procedimentos de argumentação por causa e conseqüência revela serem eles empregados não só para reforçar ou justificar as afirmações do "mestre", e as idéias e conceitos por ele expostos. Há outras funções, as quais decorrem diretamente da própria situação de enunciação (a aula): o desenvolvimento do tópico, como forma de contextualizar as informações, associando-as àquilo que o professor acredita ou supõe ser de conhecimento dos alunos, e a manifestação de juízos ou opiniões, de modo que se possa conduzir os alunos para as 
conclusões desejadas. Esse uso dos procedimentos argumentativos decorre do contrato que se estabelece entre os interactantes do evento comunicativo: o professor detém o monopólio da palavra e do saber, mas deve transmitir as informações com clareza, procurando envolver os alunos e conduzindo-as para as conclusões desejadas.

\section{Exemplos}

Exemplos são fatos individuais que ilustram uma determinada situação. Como já salientei em trabalho anterior (Galembeck, 1996, p. 60), a alusão a casos particulares representados pelos exemplos torna a explicação mais concreta, mais próxima da realidade do aluno. E o que se verifica nos exemplos a seguir:

\section{(Exemplo 10)}

Inf: eu perguntaria a você o seguinte.., e o exemplo da Ford? a Ford era uma empresa de grande porte que tinha um controle auCRATA.., DO SEU DIRIGENTE...

AL: mas... só que a Ford é uma família.., não é uma família? Não era um homem da Ford?

Inf: mas... inicialmente... era um homem só... Henry Ford... que controlava...

AL: mas há quanto tempo... atrás?

Inf: já há bastante tempo atrás... uns trinta anos atrás..

AL: Oteve espaço para crescer bastante... hoje em dia é um negocio enorme.., é uma multinacional.., quer dizer... hoje em dia é im/ é impossível...

Inf: então... você., eh... faria a seguinte distinção.., as empresas... de grande porte e multinacional seriam empresas controladas.., eh... por diversas pessoas... (NURC/RJ, 364, L. 114-128)

SIGNUM: Estud. Ling., Londrina, n. 5, p. 185-198, dez. 2002 
(Exemplo 11) “... posso olhar para uma empresa e considerar que essa empresa... pelo número de empregados que te... pela departamentalização que possui... ela é uma empresa multinacional.., vamos a um exemplo prático... a empresa... a Rede Ferroviária Federal... é a empresa... no Brasil... com o maior número de empregados... ela tem cento e cinqüenta mil empregados... conseqüentemente... dentro da divisão que você está atribuindo., embora o critério também seja válido.., essa empresa seria uma das maiores empresas do mundo... por quê? Por que o seu nível de departamentalização é muito grande... é muito maior do que.. por exemplo.., a da Volkswagen... esse é um critério válido... Mas... nós não podemos considerar... apenas... este... hã... critério como único.., para se distinguir se uma empresa é rudimentar.., pequeno porte... médio porte... grande porte... etc... o grande... a grande dificuldade que nos vamos encontrar sempre é situar a posição da empresa...” (NURC/RJ, 364, L. 172-188)

Ambos os fragmentos são extraídos de uma aula de Economia, na qual o professor discute a questão da dimensão das empresas. Para que os alunos possam compreender o assunto, ele faz referências a casos particulares: no exemplo 10, cita o caso da Ford e de seu fundador Henry Ford, para mostrar que a empresa de grande porte não pode ser uma empresa familiar. Já no exemplo 11, são mencionadas duas firmas a Rede Ferroviária Federal e a Volkswagen para mostrar que o nível de departamentalização não constitui o critério único para classificar uma empresa como multinacional e firma de grande porte. Em outras turmas, verifica-se a preocupação do "mestre" em tornar clara a exposição, pela adução de casos conhecidos dos alunos. Essa preocupação, aliás, decorre da própria situação de interação e também pode ser visualizada no exemplo a seguir, no qual o exemplo assume a forma de uma analogia: 
(Exemplo 12) - sempre que você tiver uma diferença de potencial... qualquer... diferença de matriz.., sempre essa força vai atuar em cima de uma resistência.., porque senão não tem sentido... essa forca... como que pode... atuar.., uma força atuar em cima de algo que não existe... tá? é aquela velha historia... pega um tijolo.., bota um barbante no tijolo.., faz um elefante puxar... a tensão.., aqui... independe do... do elefante e do pintinho é só função do tijolo...” (NURC/RJ, 251, L. 367-376)

Nesse fragmento, o professor explica o que é resistência e tensão por meio de uma analogia (um tijolo puxado por um pintinho ou por um elefante). Com esse procedimento, o professor aproxima dos alunos um conceito que é bastante abstrato, acerca do qual nem sempre eles têm uma noção muito clara. É, pois, um recurso para aproximar esse conceito da vivência dos alunos. Essa preocupação, aliás, é reforçada pelo empregado da linguagem informal.

\section{Testemunhos e citações}

O testemunho (referência e idéias de um autor conhecido) constitui um recurso polifônico, por meio do qual o professor incorpora idéias de terceiros à sua argumentação (Koch, 1994, p. 4), para conferir autoridade e confiabilidade à sua exposição.

(Exemplo 13) - Keynes então pensava o seguinte.., que as pessoas então retém moeda.., é:: especulando sobre.., o que vai acontecer com a rentabilidade.., dos títulos.., por exemplo se as pessoas esperam que.. uma ação éh::... vá... cair... éh vai aumentar a rentabilidade dessa ação... no mês que vem... (NURC/SP, 338, L. 342-348)

Nesse exemplo, o professor cita a opinião de Keynes para explicar com maior clareza a retenção de moeda por motivo de especulação e 
afirma que as pessoas jogam com a rentabilidade futura dos títulos, a alusão ao citado Autor que definiu o motivo de retenção de moeda dá maior credibilidade às palavras do "mestre" e, ao mesmo tempo, encaminha os alunos para a conclusão.

No exemplo a seguir, o professor cita dois autores (Whorf, Humboldt), para mostrar que a estrutura da língua dita afirma de pensamento, teoria que foi abandonada pelo estruturalismo (Sapir):

(Exemplo 14) - eu creio que nós podemos utilizar desta reflexão... para um grande número... de grupos humanos... existem então.., o verbo entre os hopi tem duas categorias... segundo Whorf... notem que eu não sei... se isto não foi completamente transformado pela lingüística moderna.., na época em que eu estive nos Estados Unidos... Sapir tinha morrido há pouco tempo e esta corrente... Edward Sapir () era gente que tinha uma importância muito grande na lingüística... isto ((tossiu)) antes de Jakobson... começar a visitar os Estados Unidos e depois o Estruturalismo lingǘstico dominou.., acho que a Lingüística de um modo geral... mas:.... o que eu quero salientar é que... sem entrarmos em hipóteses... porque a hipótese de Whorf... e de 0 como eu disse a vocês... é a hipótese... deriva... talvez de um modo geral mais claro exis/ no século dezoito existiram.., indivíduos que defenderam esta idéia $O$ e outros... que deu uma feição mais científica foi... Humboldt... a idéia que o indivíduo pensa por meio de símbolos lingüísticos... a estrutura da língua então dita a forma de pensamento." (NURC/SP, 124, L. 1899-21)

Ao citar esses vários lingüistas, o professor mostra que continua a crer na influência da estrutura da língua sobre o pensamento, apesar das idéias mais recentes e atuais de estruturalismo. Com esse procedimento, o professor reforça as idéias por ele discutidas e encaminha os alunos para a conclusão que ele supõe ser válida. 


\section{Comentários conclusivos}

Os demais procedimentos de argumentação não-discutidos nesta exposição (fatos, dados estatísticos, indução, dedução) têm baixa representatividade no corpus, representando menos de $10 \%$ das ocorrências levantadas e, por esse motivo, não foram incluídos neste trabalho. Esses recursos (particularmente a indução e a dedução) não são empregados com alta freqüência, porque requerem uma elaboração mental maior e são mais próprios da escrita. Quanto aos procedimentos aqui focalizados, cabe reiterar que seu emprego só pode ser plenamente compreendido dentro de uma situação particular de comunicação e do contrato que se estabelece entre os interactantes desse evento. Só dessa forma se pode entender a preocupação do "mestre" em expandir o tópico para contextualizar as informações veiculadas e encaminhar os alunos para conclusões válidas.

Cabe acrescentar que se privilegiou neste trabalho a perspectiva do ouvinte ou observador (hipóteses externas, segundo Ducrot; Anscombre, 1976, p. 19). Em trabalho posterior, deverão ser estudadas as hipóteses internas ou mecanismos que intervêm na descrição semântica.

\section{Referências bibliográficas}

CHARAUDEAU, P. L'interlocution comme interaction de stratégies discoursives. Verbum, VII, fasc. 213, p. 165-183, 1984.

DUCROT, O. e ANSCOMBRE, J. C. L'argumentaation dans la langue. Langages. Argumentation et discours scientifique. n. 42, p. 5-27, 1976.

GALEMBECK, P. T. Envolvimento do ouvinte na interação assimétrica. Intercambio, n. 5, p. 55-66, 1998.

SIGNUM: Estud. Ling., Londrina, n. 5, p. 185-198, dez. 2002 
GARCIA, O. M. Comunicação em prosa moderna. Aprenda a escrever, aprendendo a pensar. 4. ed. Rio de Janeiro: Fundação Getúlio Vargas, 1976.

KERBRAT ORECHION, C. Les interactions verbales. Paris: Armand Colin, 1990. 